\title{
Amino Acid Interconversions in the Fetal-Placental Unit: The Animal Model and Human Studies In Vivo
}

\author{
IRENE CETIN \\ Obstetrics and Gynecology, San Paolo Department of Medicine, Surgery, and Odontoiatry, University of \\ Milano School of Medicine, via A. di Rudini', 8, 20142 Milano, Italy
}

\begin{abstract}
ABST
Fetal growth and development are dependent upon the ade-
quate provision of oxygen and substrates from the maternal
circulation. The need for amino acids is related to protein syn-
thesis, interconversion to other substrates, and oxidation. Amino
acids cross the placenta by active transport systems, and their
concentrations in the fetus are higher than in the mother. In
addition, most amino acids are extensively metabolized within
the placenta, and, for some nonessential amino acids, placental
synthesis has been demonstrated in chronically catheterized fetal
lambs. Interorgan cycling between the fetal liver and placenta has
been hypothesized for nonessential amino acids like glycine and
serine. Amino acids are oxidized within the fetal tissues, partic-
ularly in liver and muscle, with differences between amino acids
and in relation to metabolic state. In human pregnancies, mater-
nal-fetal transfer rates have been investigated in vivo by stable
isotope methodologies performed at fetal blood sampling. The
transfer rate of nonessential amino acids like glycine is signifi-
cantly lower than for essential amino acids like leucine, confirm-
\end{abstract}
Amino acids represent key nutrients during intrauterine life. Placental mechanisms accounting for amino acid transfer from the mother to the fetus have been thoroughly described in the last $20 \mathrm{y}$. The relevance of these mechanisms to fetal growth is strongly suggested by a number of studies demonstrating differences in amino acid placental transfer and metabolism occurring in human pregnancies associated with IUGR. The primary objective of this review is to integrate this recent information obtained in human pregnancies with the wide knowledge that has developed around the animal model.

Some years ago, it seemed adventurous to propose the concept that pregnancy represented a metabolic state of not just a mother and a fetus but a three-compartment model of mother-

Received April 25, 2000; accepted September 10, 2000.

Correspondence and reprint requests: Irene Cetin, M.D., Obstetrics and Gynecology, San Paolo Department of Medicine, Surgery, and Odontoiatry, University of Milano School of Medicine, via A. di Rudini', 8, 20142 Milano, Italy.

Supported in part by a European Economic Community (EEC) grant BMH4-98-3621 and a grant from the Italian Ministry of University and Scientific and Technologic Research (Ministero Università e Ricerca Scientifica e Tecnologica: MURST). ing glycine synthesis in the fetoplacental unit also in human pregnancies. Moreover, when a steady state model is applied, the fetal-maternal ratio for $\left[1-{ }^{13} \mathrm{C}\right]$ leucine is significantly reduced in pregnancies associated with intrauterine growth restriction, reflecting a decrease in leucine placental transfer and/or an increase in protein catabolism in the fetoplacental unit. This reduction is proportional to the degree of severity of intrauterine growth restriction but is significant also in those intrauterine growthrestricted fetuses with normal oxygenation and acid-base status.

(Pediatr Res 49: 148-154, 2001)
Abbreviations
IUGR, intrauterine growth restriction
DR, disposal rate
KIC, ketoisocaproic acid
BCAA, branched-chain amino acids
F/M, fetal/maternal

placenta-fetus. The most-used animal model to study the relative contributions of each of these compartments to amino acid metabolism has been the pregnant sheep, principally because it is feasible in this species to catheterize chronically the maternal and fetal circulations.

Uterine and umbilical uptakes can be calculated using an application of the Fick principle (1) as the product of concentration differences across the uterine circulation (uterine arterial concentration-uterine venous concentration) or the umbilical circulation (umbilical venous concentration-umbilical arterial concentration) times the uterine or the umbilical blood flow to yield uterine and umbilical uptakes, respectively. Analysis by this model of uterine and umbilical amino acid uptakes has demonstrated that there is a large uptake of most neutral and basic amino acids by the pregnant uterus (2) and, similarly, a large uptake of amino acids by the fetus (3). Uterine and umbilical uptakes of individual amino acids are not necessarily equal due to utilization or production by the uteroplacental tissues. These early studies pointed to the fact that in the normal fetal lamb, the uptake of amino acids from the umbil- 
ical circulation is in excess of what is needed for nitrogen accretion, consistent with a very high rate of ammonia production by the pregnant uterus (4). These studies also showed that some amino acids were not significantly taken up by the uterine circulation, whereas, for some others, there was a net release from the fetus to the placenta, i.e. they demonstrated higher concentrations in the umbilical artery than in the umbilical vein with a significantly negative umbilical venoarterial concentration difference. It, thus, became clear that the placenta was not just acting as an amino acid concentrator toward the fetus but that complex interactions were involved, and placental metabolism was part of an integrated system together with fetal organ metabolism.

\section{Placental Amino Acid Uptake and Exchanges}

The role of the placenta in amino acid metabolism for protein synthesis, oxidation, transamination, and synthesis of some nonessential amino acids has been suggested by several observations. First is the demonstration that there is a net ammonia production by the placenta that is delivered into both the uterine and umbilical circulations $(2,4)$. Moreover, there is a high activity for the BCAA transferases in both human (5) and sheep (6) placentas, suggesting a significant metabolism of the BCAA to their corresponding keto acids.

Basic information about uteroplacental amino acid metabolism in vivo can be obtained by comparison of uterine and umbilical amino acid uptakes. Even though uterine uptake involves the myometrium, besides the placenta and fetus, this can be considered a relatively insignificant contribution (1). Therefore, placental amino acid uptake can be calculated in the ovine model as the difference between uterine and umbilical uptakes.

However, the application of the Fick principle to uterine and umbilical concentration differences presents some potential difficulties mainly related to the relatively small concentration differences of most amino acids, with a less then $10 \%$ coefficient of extraction particularly across the uterine circulation, which can be below the coefficient of error for that amino acid. Therefore, a large number of measurements are needed to demonstrate significant amino acid concentration differences.

A significant contribution in clarifying this subject has come recently from a study in 18 pregnant sheep studied under normal physiologic conditions in which both uterine and umbilical amino acid uptakes were measured simultaneously in the last part of gestation (7). Significant uterine and umbilical uptakes were obtained for all the essential amino acids, and, for eight amino acids, there was a significant difference between uterine and umbilical uptake, demonstrating significant uteroplacental utilization for these amino acids. However, although some amino acids showed a net placental uptake (valine, leucine, isoleucine, serine, glutamate), others were significantly released by the placenta (methionine, glycine, glutamine).

These results confirmed findings obtained in previous studies showing that glycine is not significantly taken up by the uterine circulation (2), whereas, at the same time, there is a significant release from the placenta to the fetus $(3,8)$. The opposite is true for serine: a significant uterine uptake coupled with a significant release from the fetus toward the placenta. Because glycine is not significantly taken up by the pregnant uterus, the quite large uptake of glycine from the umbilical circulation has to be accounted for by placental production. Glycine can be produced from serine, and this possibility has been demonstrated by tracer serine infusion into the fetal circulation. When stable isotopes are applied, amino acid DR can be calculated by knowing the isotope infusion rate and the enrichment of the amino acid in plasma at isotopic equilibrium. The term enrichment is analogous to the term specific activity, commonly used with radioactive tracers, and is an expression of the relative abundance of isotope. Serine demonstrated a very high DR (Table 1), with plasma glycine enrichment approximately $60 \%$ of serine enrichment (9). Approximately $45 \%$ of infused tracer was lost in the placenta, and $15 \%$ of it was converted to glycine and released in the umbilical circulation. Moreover, when tracer serine was infused into the maternal circulation, there was no significant transport of maternal plasma serine across the placenta into the fetal circulation (10), whereas there was significant labeling of both maternal and fetal glycine. These results could not clarify whether fetal tracer glycine was originating from maternal tracer glycine or was formed from tracer serine within the placenta. However, when tracer glycine was infused into the mother, only a very low fraction was appearing into the fetal circulation. A further proof that maternal serine is used to form glycine in the placenta came from a study conducted in twin pregnancies. Tracer serine was infused into the uterine artery of one pregnant horn: although no tracer serine could be detected in either infused or noninfused fetal circulations, tracer glycine enrichments were significantly higher in the uterine venous and umbilical vessels of the infused placenta (11). Therefore, although there is no transfer from the maternal to the fetal circulation, both the maternal and fetal surfaces of the placenta have been shown to be permeable to serine, and the placenta is capable of producing glycine from serine infused into both the maternal $(11)$ and fetal $(9,12)$ circulations (Fig. 1). The consequence of this serine-to-glycine flux is the production of methylenetetrahydrofolate, which is also produced from glycine oxidation within the placenta and can be used for remethylation of homocysteine as well as for other metabolic pathways, making carbon atoms available to the placenta.

Table 1. Mean fetal arterial plasma concentrations ( $\left.\left[C_{f}\right]\right), D R$, and rates of oxidation $\left(R_{o x}\right)$ for eight amino acids

\begin{tabular}{lcccc}
\hline & $\begin{array}{c}{\left[\mathrm{C}_{\mathrm{f}}\right]} \\
(\mu \mathrm{M})\end{array}$ & $\begin{array}{c}\mathrm{DR} \\
\left(\mu \mathrm{mol} \cdot \mathrm{min}^{-1} \cdot \mathrm{kg}^{-1}\right)\end{array}$ & $\begin{array}{c}\mathrm{R}_{\mathrm{ox}} \\
(\%)\end{array}$ & Reference \\
\hline leucine & 168 & 8.7 & 20.4 & 13 \\
lysine & 90 & $\mathrm{na}$ & 9.0 & 15 \\
threonine & 466 & 8.9 & 4.7 & 16 \\
glycine & 406 & 12.4 & 11.3 & 17 \\
serine & 767 & 42.5 & 7.9 & 9 \\
alanine & 295 & 15.5 & 61 & 18 \\
glutamate & 59 & 11.9 & 37 & 12 \\
glutamine & 384 & 19.9 & na & 21 \\
\hline
\end{tabular}

Data refer to studies performed in chronically catheterized pregnant sheep. na: not available. 
Glutamate is another amino acid that is not significantly taken up by the uterine circulation $(2,7)$. This is accompanied by a net release from the fetus toward the placenta, opposite in direction to the flux of most other amino acids and similar to the net flux of serine into the placenta, suggesting a unique role for both of these two nonessential amino acids (Fig. 1).

The three BCAA valine, leucine, and isoleucine presented uterine uptakes significantly greater then their umbilical uptakes (7), the difference being accounted for by a significant placental uptake and catabolism. Tracer studies have shown that when tracer leucine is infused in the fetal circulation, approximately $10 \%$ is deaminated within the placenta to its keto acid KIC (13). Therefore, leucine is significantly taken up from the maternal circulation into the placenta where it is in part deaminated to KIC. Then both leucine and KIC are transferred to the fetus (Fig. 1). The $\mathrm{NH}_{3}$ produced within the placenta is released toward the maternal circulation but can also interact with $\alpha$-ketoglutarate to form glutamate. Therefore, the placenta utilizes glutamate from two main sources: an endogenous source of glutamate from BCAA transamination as well as an exogenous source from the uptake of fetal glutamate.

Fetal glutamate DR have been measured by means of both ${ }^{14} \mathrm{C}$ and ${ }^{13} \mathrm{C}$ glutamate infusion into the peripheral fetal circulation, yielding values similar to those obtained for some other amino acids that present much higher concentrations in the fetus, as shown in Table 1 (12). The striking feature of glutamate DR is that the placenta extracts almost $90 \%$ of the tracer glutamate carried by the umbilical circulation, representing a remarkably high placental clearance of fetal plasma glutamate. A relatively small fraction of the fetal glutamate taken up by the placenta is returned to the fetus as glutamine, shuttling to the fetus some of the ammonia produced by placental amino acid catabolism. However, the glutamine/

\section{MATERNAL POOL \\ UTERO PLACENTA \\ FETAL
POOL}

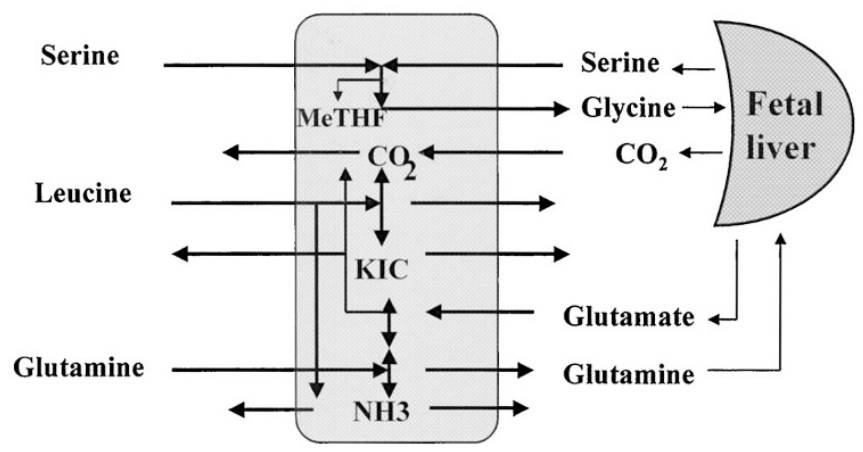

Figure 1. Diagram of amino acid placental exchanges between maternal and fetal plasma pools in chronically catheterized pregnant sheep. Serine is taken up by the placenta from both maternal and fetal circulations: glycine is produced and released in the fetal circulation, and then taken up by fetal liver and partly converted to serine and $\mathrm{CO}_{2}$. Glutamine is taken up by the maternal circulation but also produced from glutamate within the placenta, released into the fetal circulation, and significantly converted to glutamate within the fetal liver. Leucine is also taken up by the maternal circulation, deaminated to KIC within the placenta, and then released into the fetal circulation together with KIC. Placental amino acid utilization leads to ammonia production. glutamate enrichment ratio in fetal arterial plasma is only $6 \%$. The predominant pathway of glutamate in the placenta is represented by oxidation, accounting also for a large fraction of placental ammonia excretion. Glutamate oxidation generates NADPH, which is used in steroidogenesis and could be linked to the endocrine changes associated with parturition.

The role of placental metabolism in determining the supply of alanine to the fetus has also been investigated by tracer methodologies. Although there is a significant umbilical uptake of alanine, the direct transplacental alanine flux under physiologic maternal alanine concentrations accounts for only approximately $2 \%$ of the alanine flux from placenta to fetus (14). However, when maternal alanine concentration is raised, the umbilical uptake increases significantly. Placental alanine utilization also increases significantly, but the direct maternalfetal alanine flux contributes only $8 \%$ of the total alanine flux from placenta to fetus. Therefore, when considering only data obtained from tracer placental exchange, the placenta seems relatively impermeable to alanine. However, the 2-fold increase in net fetal alanine uptake obtained when maternal alanine concentrations are increased 4-fold demonstrates the presence of a placental alanine pool that is turning over rapidly and dilutes the tracer enrichment.

\section{Amino Acid Interconversions by Fetal Tissues}

The study by Chung et al. (7) confirming previous studies (3, 8) demonstrated also that umbilical uptake of essential amino acids is 1.8-3.3 times in excess of their estimated normal fetal accretion rates. These data point again to a significant amino acid oxidation within the fetus, which has been demonstrated by tracer methodology for leucine (13), lysine (15), and threonine (16) among the essentials and for glycine (17), serine (9), alanine (18), and glutamate (19) of the nonessentials (Table 1).

Fetal liver. The relevance of amino acid metabolism within the fetus has been further explored by the evaluation of fetal organ metabolism. Instrumentation of fetal hepatic vein has made it possible to compare umbilical and hepatic amino acid concentration differences (8). Interesting observations have been reported for glycine, which is released by the placenta into the umbilical circulation and then taken up by the fetal liver, whereas serine is released by the fetal liver with no significant net flux between the placenta and fetal blood.

Based on these observations, an interorgan cycling has been suggested between the fetal liver and the placenta on the hypothesis that placental production of glycine from serine is coupled with serine production within the fetal liver from glycine. In adults, glycine and serine are interconvertible by the action of serine hydroxymethyltransferases and the glycine cleavage system.

This possibility has been demonstrated using stable isotope methodologies that allow the measurement of net tracer production. Glycine labeled with carbon 13 in the first position was infused into the fetal circulation, and tracer concentration differences were measured across the hepatic circulation in chronically catheterized fetal lambs (17). A major finding of this study was that together with a small uptake of tracer glycine by the placenta $(6 \%)$ and virtually no transfer of tracer 
glycine into the maternal circulation, there was a large uptake of tracer glycine by the fetal liver (approximately 50\%), and this uptake was accompanied by a significant release of labeled serine and carbon dioxide. Figure 2 presents the molar tracer concentration differences for glycine, serine, and carbon dioxide across the fetal hepatic circulation. With tracer $\left[1-{ }^{13} \mathrm{C}\right] \mathrm{g}$ lycine, the molar ratio of the differences is consistent with the action of the glycine cleavage system and serine hydroxymethyltransferase, so that $2 \mathrm{~mol}$ of glycine are converted into 1 mol of serine and the release of $1 \mathrm{~mol}$ of $\mathrm{CO}_{2}$. The reaction sequence can be summarized as follows:

Equation 1

$$
2 \text { glycine }+\mathrm{H}_{2} \mathrm{O}=\text { serine }+\mathrm{CO}_{2}+\mathrm{NH}_{3}+2 \mathrm{H}
$$

During the infusion of $\left[1-{ }^{13} \mathrm{C}\right]$ glycine as tracer, labeled carbon dioxide and serine were produced in equimolar amounts and tracer glycine used at twice the rate (Fig. 2). The labeled $\mathrm{CO}_{2}$ released by the liver was approximately $70 \%$ of the labeled $\mathrm{CO}_{2}$ produced by the fetus. Therefore, the fetal liver is the major site of fetal plasma glycine decarboxylation and of serine synthesis from plasma glycine.

The comparison of umbilical and hepatic amino acid concentration differences demonstrated also a significant uptake of glutamine by the fetal liver (8), greater than that of any other amino acid. Glutamine can be used as gluconeogenic precursor; however, no significant liver gluconeogenesis has been demonstrated in fetal life (20). Because the fetal liver releases significant amounts of glutamate that is then taken up by the placenta (8), these observations suggested glutamine-glutamate exchange between the fetal liver and the placenta. This hypothesis has been explored by infusing $\left[1,2-{ }^{13} \mathrm{C}_{2}\right]$ glutamine into the peripheral fetal circulation (21), which led to significant labeling of fetal glutamate molecules with a glutamate/glutamine enrichment ratio of approximately $28 \%$. The fetal liver is the primary site of glutamine-to-glutamate conversion with approximately $45 \%$ of glutamine hepatic uptake converted to glutamate. However, although there is rapid conversion of plasma glutamine to plasma glutamate in the fetal liver, there is only a small reciprocal conversion of glutamate to glutamine within the placenta, whereas glutamate is mainly oxidized within the uteroplacental tissues (19).

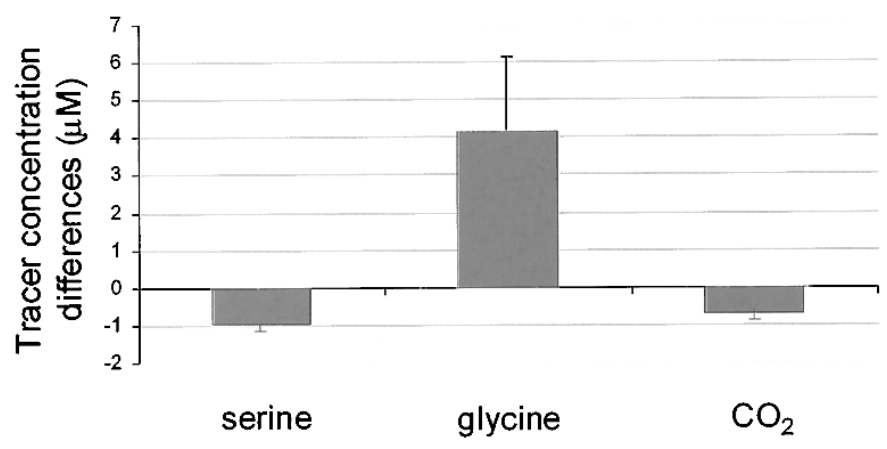

Figure 2. Hepatic input-hepatic venous plasma concentration differences for $\left[1-{ }^{13} \mathrm{C}\right]$ glycine, $\left[1-{ }^{13} \mathrm{C}\right]$ serine, and ${ }^{13} \mathrm{CO}_{2}$ during tracer glycine infusion in the peripheral circulation of chronically catheterized fetal lambs [adapted from (17)].
The possible relationship between endocrine changes during parturition and glutamate and glutamine fetal hepatic metabolism has been studied using a fetal infusion of dexamethasone to induce parturition. This has led to a decrease by one fourth in fetal hepatic glutamate release and in a one-fifth decrease in placental glutamate uptake, confirming that steroid-induced parturition is associated with significant changes in fetal hepatic and placental glutamate metabolism(22).

Fetal muscle. By catheterization of the fetal femoral vein, it is possible to measure uptake across the hindlimb. This methodology allows the investigation of carcass metabolism during intrauterine life. At the end of intrauterine life, the fraction of the fetal weight represented by skin, muscle, and skeleton is approximately $70 \%$ of body weight, thus, a large fraction of the tissues of the body. When comparing metabolic quotients obtained simultaneously in fetal and maternal hindlimb, significantly higher glucose/oxygen quotients have been reported in the fetus (23). Moreover, the same study showed that the fetal hindlimb has a much lower arteriovenous difference for oxygen, indicating a much higher rate of perfusion for these fetal tissues.

In the fed state, the hindlimb shows a significant uptake of 21 amino acids for a net total nitrogen uptake of $132 \pm 21 \mathrm{mg}$ $\mathrm{N} \cdot \mathrm{d}^{-1} \cdot 100 \mathrm{~g}^{-1}(24)$. Significant uptakes have been demonstrated for the gluconeogenic amino acids glutamine, glutamate, and alanine and for the BCAA leucine, valine, and isoleucine (24, 25). Significantly, positive plasma arteriovenous concentration differences across the fetal hindlimb have also been found for glycine and serine $(9,24)$, indicating net amino acid hindlimb uptake. At the same time, both tracer serine and glycine show a dilution of their enrichments from the umbilical artery to the fetal femoral vein. The uptake of tracer serine is accompanied by a significant release of tracer $\mathrm{CO}_{2}$ by the fetal hindlimb that accounts for approximately $80 \%$ of decarboxylation of serine by the whole fetus (9).

Significant changes in amino acid uptakes by the hindlimb have been shown during maternal fasting. After several days of maternal fasting, glucose supply from the mother to the fetus decreases by $60 \%$, whereas the umbilical uptake of free amino acids from the placenta does not change (26). Oxygen consumption also remains unchanged, but the rate of amino acid catabolism appears to double, suggesting that either tissue synthesis is reduced and/or that the fetus is catabolizing previously formed proteins.

Skeletal muscle plays an important metabolic role in the adaptation of the fetus to maternal fasting: although glutamine and alanine have a positive uptake in the fed state, after $5 \mathrm{~d}$ of maternal fasting, they show a significant efflux together with a significant decrease in the uptake of glutamate (25). At the same time, there is a significant increase in the hindlimb uptake of the three BCAA, mainly for leucine (25). The efflux of glutamine may reflect the mobilization of carbon derived from the degradation of amino acids like the BCAA, potentially for new glucose synthesis within the fetal liver. Alanine release is probably due to the conversion from pyruvate originated from glucose via glycolysis within the glucose-alanine cycle. 


\section{Amino Acid Exchanges in Human Pregnancies}

In humans, the concentration of amino acids is higher in fetal than in maternal blood (27-29) in agreement with the presence of active transport systems within the microvillous and basal membranes of the placenta. However, the presence of identified transport systems for an amino acid does not determine whether or not it is transported across the trophoblast into the fetal circulation, because placental amino acid exchange involves 1 ) the direct energy-dependent transfer of amino acids; 2) placental metabolism and consumption of amino acids; and 3) placental metabolism and processing (interconversion) of amino acids.

The recent years have seen incredible changes in the development of new tools for the study of the human fetus in its intrauterine environment. Among these is the development of techniques to sample fetal blood in utero and the application of stable isotope methodologies to human pregnancies.

Percutaneous umbilical blood sampling under ultrasonic guidance has provided the opportunity to measure glucose and amino acid concentrations in a relatively unstressed condition unaffected by parturition and at different gestational ages (30). The comparison between fetal and maternal concentrations of a given substrate can be used as an index of transport and metabolism. However, because the placenta is a very active organ and interorgan exchange has been demonstrated for nonessential amino acids in chronically catheterized pregnant sheep, results obtained only by the study of amino acid concentrations in fetal and maternal blood can be misleading. In essence, the presence of a substrate in the fetal circulation does not necessarily mean that this substrate was supplied to the fetus from the maternal circulation. For nonessential amino acids, the possibility of production within the fetoplacental compartment can be investigated using stable isotope methods.

Stable isotopes can be used in human pregnancies due to their safety, but the studies are limited by the fact that the tracer has to be infused in the mother and also that only one or at the most two fetal samples can be obtained. The comparison of fetal and maternal enrichment of labeled compounds at the time of fetal blood sampling or cesarean delivery provides information on the transplacental passage of nutrients (31) as well as on fetal and placental nutrient metabolism $(32,33)$.

The first study to provide kinetic data concerning amino acid metabolism and protein turnover in the human fetus was performed at the time of elective cesarean delivery in normal term pregnancies (32). $1-\left[1-{ }^{13} \mathrm{C}\right]$ leucine and $1\left[{ }^{15} \mathrm{~N}\right]$ phenylalanine were infused continuously into the maternal circulation $4 \mathrm{~h}$ before fetal extraction to reach maternal steady state. At the time of cesarean section, maternal arterialized and uterine venous samples were obtained. Umbilical blood flow was calculated by an ultrasonic transit-time method before cord clamping, and then the umbilical artery and vein were sampled. The rates of disappearance of leucine and phenylalanine into the fetal compartment were 7.22 \pm 0.83 and $2.69 \pm 0.39 \mu \mathrm{mol} / \mathrm{min}$, respectively, which represented only approximately $5 \%$ of their appearance rates in the maternal plasma pool. About one sixth of the umbilical uptake of leucine was oxidized in the fetus and about one half reexported to the placenta as KIC, which is different from the sheep in which there is a net export of KIC to the fetus (13). During maternal $1\left[{ }^{15} \mathrm{~N}\right]$ phenylalanine infusion, there was a significant ${ }^{15} \mathrm{~N}$ enrichment of tyrosine in the fetal circulation with higher enrichments in the umbilical artery than in the umbilical vein, implying that tyrosine was produced from phenylalanine into the fetal compartment.

The evaluation of placental transport and fetal DR in vivo in human pregnancies, however, relies on measurements of umbilical blood flow and arteriovenous differences obtained at the time of cesarean section in an acute situation, which could be not well representative of the steady state intrauterine environment. Therefore, the appearance of a tracer amino acid into the fetal circulation after maternal infusion has been evaluated also at the time of fetal blood sampling in a relatively undisturbed condition. In this situation, only umbilical venous samples are obtained, and their enrichments compared with the maternal will represent a complex function of fetal and placental metabolism and also of placental permeability.

Two different models have been developed: $a$ ) nonsteady state kinetics by maternal bolus infusion that allows the study of unidirectional fluxes; and $b$ ) steady state kinetics by maternal bolus followed by a continuous maternal infusion to study placental permeability together with fetoplacental metabolism.

Studies using a maternal bolus have demonstrated that in normal pregnancies, there are significant differences in the in vivo transplacental transport of an essential amino acid like leucine compared with a nonessential amino acid like glycine (31). $1\left[1-{ }^{13} \mathrm{C}\right]$ glycine and $1\left[1-{ }^{13} \mathrm{C}\right]$ leucine were infused into a maternal peripheral vein, and umbilical venous samples were obtained within $15 \mathrm{~min}$ from the bolus. The ratios of amino acid placental transfer were determined by the F/M enrichment ratio (Fig. 3). Fetal blood sampling was performed after a wide range of times from the bolus, allowing calculation of nonlinear regression equation. The curves for leucine and glycine were significantly different. For glycine, the rate of transfer was significantly lower with a glycine/leucine ratio of $0.16 \pm$ 0.02 , indicating that there is a significant production of glycine within the fetal-placental unit, similar to findings obtained in sheep.

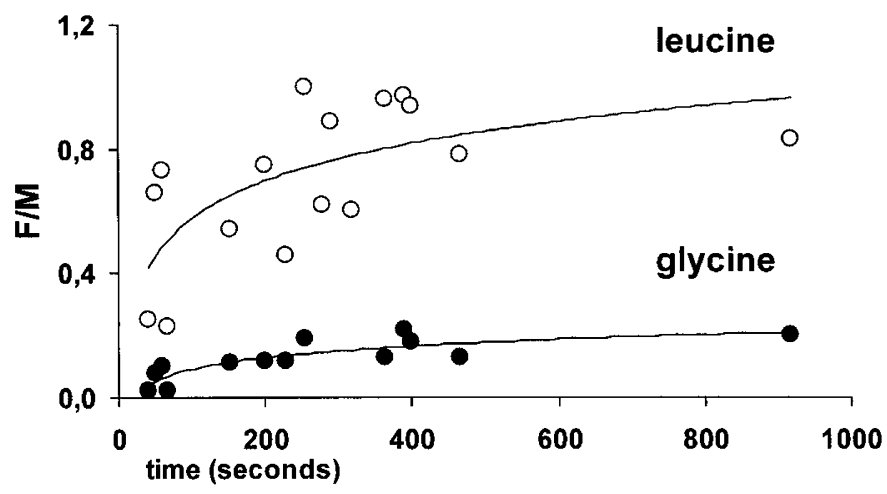

Figure 3. F/M enrichment ratio for the nonessential amino acid glycine and for the essential amino acid leucine in relation to time elapsed between a maternal bolus of $\left[1-{ }^{13} \mathrm{C}\right]$ glycine and $\left[1-{ }^{13} \mathrm{C}\right]$ leucine and fetal blood sampling. Data refer to studies performed in normal human pregnancies undergoing fetal blood sampling for prenatal diagnosis during the second half of gestation. The curves are significantly different $(p<0.0001)$ [adapted from (31)]. 
With the same approach, very recently $1\left[1-{ }^{13} \mathrm{C}\right]$ phenylalanine and $1\left[1-{ }^{13} \mathrm{C}\right]$ proline have been infused together with $1[1-$ $\left.{ }^{13} \mathrm{C}\right]$ glycine and $1\left[1-{ }^{13} \mathrm{C}\right]$ leucine in both normal and IUGR pregnancies (34): in normal pregnancies, the $\mathrm{F} / \mathrm{M}$ enrichment ratio was significantly higher (approximately three fourths) for the essential amino acids phenylalanine and leucine than for the nonessential amino acids glycine and proline ( $\mathrm{F} / \mathrm{M}$ less than one fourth). These results suggest that the two essential amino acids leucine and phenylalanine rapidly cross the placenta. Moreover, the F/M enrichment ratio was significantly lower in IUGR pregnancies than in normal pregnancies for these two essential amino acids (approximately one half) but not for glycine and proline (34).

The first study demonstrating the normal steady state F/M plasma enrichments for leucine was performed in pregnancies of the third trimester with a maternal primed-constant infusion of $1\left[1-{ }^{13} \mathrm{C}\right]$ leucine and umbilical venous samples taken approximately $2 \mathrm{~h}$ after the start of the infusion (33). In this study, the $\mathrm{F} / \mathrm{M}$ enrichment ratios for leucine in normal pregnancies were $0.89 \pm 0.02$, approximately $20 \%$ higher than the F/M ratios of 0.70 reported at cesarean delivery (32). This difference can be reflecting the different conditions, i.e. the surgical stress of cesarean delivery and the time required for flow measurements during which the fetus was exteriorized.

Therefore, in normal pregnancies under undisturbed conditions during the latter part of gestation, almost $90 \%$ of fetal plasma leucine is derived from the maternal circulation with a relatively small entry (approximately 10\%) from protein breakdown within the placental and fetal tissues. This is significantly different from results obtained in pregnant sheep in which only $46 \%$ of fetal leucine is of maternal origin (35), representing a major difference within the two species, probably due to differences in placental permeability. However, data obtained in human pregnancies are supportive of data obtained in pregnant sheep in that significant differences are observed between essential and nonessential amino acids, confirming that in human pregnancies also, amino acid interconversions are present in the fetoplacental compartment.

In the same study, the F/M enrichment ratio for leucine was significantly lower in IUGR $(0.70 \pm 0.08)$ than in normal pregnancies. This difference can be due to an increase in protein breakdown that dilutes the fetal plasma enrichment and/or to a decrease in the transplacental transfer rate. The F/M ratio progressively decreased with increasing degrees of clinical severity defined according to fetal arterial Doppler velocimetry and fetal heart rate pattern (33). This classification of clinical severity has previously shown that changes in oxygen content, lactate concentration, and acid-base status in IUGR fetuses are associated with altered umbilical arterial Doppler velocimetry and fetal heart rate (36). These data further provide evidences concerning fetuses with in utero reduction of fetal growth but normal umbilical arterial flows, fetal heart rate, oxygenation, and acid-base status. Interestingly, these relatively normal IUGR pregnancies also show a decrease in FM amino acid concentration differences (29) accompanied by a significant reduction in the $\mathrm{F} / \mathrm{M}$ leucine enrichment ratio (33).
The alterations in amino acid placental transfer and metabolism seem to be a common feature of fetal growth restriction, independently from changes in oxygenation and acid-base status. This suggests that these alterations are not a result of a general reduction in uterine and/or umbilical blood flows of IUGR pregnancies. On the contrary, specific alterations in placental transport systems in IUGR have been described in vitro on both the molecular and functional level (37). Potential strategies for in utero nutritional supplementation need to be developed taking into account the very complex amino acid interactions occurring within the placenta, the possible increase in oxygen consumption, and the relationship with growth factors.

\section{REFERENCES}

1. Meschia G, Battaglia FC, Hay WW, Sparks JW 1980 Utilization of substrates by the ovine placenta in vivo. Fed Proc 39:245-249

2. Holzman IR, Lemons JA, Meschia G, Battaglia FC 1979 Uterine uptake of amino acids and glutamine-glutamate balance across the placenta of the pregnant ewe. J Dev Physiol 1:137-149

3. Lemons JA, Adcock III EW, Jones Jr MD, Naughton MA, Meschia G, Battaglia FC 1976 Umbilical uptake of amino acids in the unstressed fetal lamb. J Clin Invest 58:1428-1434

4. Holzman IR, Lemons JA, Meschia G, Battaglia FC 1977 Ammonia production by the pregnant uterus. Proc Soc Exp Biol Med 156:27-30

5. Jaroszewicz L, Jozwik M, Jaroszewicz K 1971 The activity of aminotransferases in human placenta in early pregnancy. Biochem Med 5:436-439

6. Goodwin GW, Gibboney W, Paxton R, Harris RA, Lemons JA 1987 Activities of branched-chain amino acid aminotransferase and branched-chain 2-oxo acid dehydrogenase complex in tissues of maternal and fetal sheep. Biochem J 242:305-308

7. Chung M, Teng C, Timmerman M, Meschia G, Battaglia FC 1998 Production and utilization of amino acids by ovine placenta in vivo. Am J Physiol 274:E13-E22

8. Marconi AM, Battaglia FC, Meschia G, Sparks JW 1989 A comparison of amino acid arteriovenous differences across the liver and placenta of the fetal lamb. Am J Physiol 257:E909-E910

9. Cetin I, Fennessey PV, Sparks JW, Meschia G, Battaglia FC 1992 Fetal serine fluxes across fetal liver, hindlimb, and placenta in late gestation. Am J Physiol 263:E786E793

10. Geddie G, Moores R, Meschia G, Fennessey PV, Wilkening RB, Battaglia FC 1996 Comparison of leucine, serine, and glycine transport across the ovine placenta. Placenta 17:619-627

11. Moores Jr RR, Rietberg CC, Battaglia FC, Fennessey PV, Meschia G 1993 Metabolism and transport of maternal serine by the ovine placenta: glycine production and absence of serine transport into the fetus. Pediatr Res 33:590-594

12. Moores Jr RR, Carter BS, Meschia G, Fennessey PV, Battaglia FC 1994 Placental and fetal serine fluxes at midgestation in the fetal lamb. Am J Physiol 267:E150-E155

13. Loy GL, Quick AN, Hay WW, Meschia G, Battaglia FC, Fennessey PV 1990 Fetoplacental deamination and decarboxylation of leucine. Am J Physiol 259:E492E497

14. Timmerman M, Chung M, Wilkening RB, Fennessey PV, Battaglia FC, Meschia G 1998 Relationship of fetal alanine uptake and placental alanine metabolism to maternal plasma alanine concentration. Am J Physiol 275:E942-E950

15. Meyer PR, Peterson RG, Bonds DR, Meschia G, Battaglia FC 1981 Rates of protein synthesis and turnover in fetal life. Am J Physiol 240:E320-E324

16. Anderson AH, Fennessey PV, Meschia G, Wilkening RW, Battaglia FC 1997 Placental transport of threonine and its utilization in the normal and growth-restricted fetus. Am J Physiol 272:E892-E900

17. Cetin I, Fennessey PV, Quick Jr AN, Marconi AM, Meschia G, Battaglia FC, Sparks JW 1991 Glycine turnover and oxidation and hepatic serine synthesis from glycine in fetal lambs. Am J Physiol 260:E371-E378

18. Guyton TS, de Wilt H, Fennessey PV, Meschia G, Wilkening RB, Battaglia FC 1993 Alanine umbilical uptake, disposal rate, and decarboxylation rate in the fetal lamb. Am J Physiol 265:E497-E503

19. Moores Jr RR, Vaughn PR, Battaglia FC, Fennessey PV, Wilkening RB, Meschia G 1994 Glutamate metabolism in fetus and placenta of late-gestation sheep. Am J Physiol 267:R89-R96

20. Hay Jr WW, Sparks JW, Quissel BJ, Battaglia FC, Meschia G 1981 Simultaneous measurements of umbilical uptake, fetal utilization rate, and fetal turnover rate of glucose. Am J Physiol 240:E662-E668

21. Vaughn JR, Lobo C, Battaglia FC, Fennessey PV, Wilkening RB, Meschia G 1995 Glutamine-glutamate exchange between placenta and fetal liver. Am J Physiol 368:E705-E711

22. Barbera A, Wilkening RW, Battaglia FC, Meschia G 1997 Metabolic alterations in the fetal hepatic and umbilical circulations during glucocorticoid induces parturition in sheep. Pediatr Res 41:242-248

23. Singh S, Sparks JW, Meschia G, Battaglia FC, Makowski EL1984 Comparison of fetal and maternal hindlimb metabolic quotients in sheep. Am J Obstet Gynecol 149:441-449 
24. Wilkening RB, Boyle DW, Teng C, Meschia G, Battaglia FC 1994 Amino acid uptake by the fetal ovine hindlimb under normal and euglycemic hyperinsulinemic states. Am J Physiol 266:E72-E78

25. Liechty EA, JA Lemons 1984 Changes in ovine fetal hindlimb amino acid metabolism during maternal fasting. Am J Physiol 246:E430-E435

26. Lemons JA, Schreiner RL 1983 Amino acid metabolism in the ovine fetus. Am J Physiol 244:E459-E466

27. Cetin I, Marconi AM, Bozzetti P, Piceni Sereni L, Corbetta C, Pardi G, Battaglia FC 1998 Umbilical amino acid concentrations in appropriate and small for gestational age infants: a biochemical difference present in utero. Am J Obstet Gynecol 158:120-126

28. Cetin I, Corbetta C, Piceni Sereni L, Marconi AM, Bozzetti P, Pardi G, Battaglia FC 1990 Umbilical amino acid concentrations in normal and growth-retarded fetuses sampled in utero by cordocentesis. Am J Obstet Gynecol 162:253-261

29. Cetin I, Ronzoni S, Marconi AM, Perugino G, Corbetta C, Battaglia FC, Pardi G 1996 Maternal concentrations and fetal-maternal concentration differences of plasma amino acids in normal (AGA) and intrauterine growth-restricted pregnancies. Am J Obstet Gynecol 174:1575-1583

30. Marconi AM, Cetin I, Buscaglia M, Pardi G1992 Midgestation cord sampling: what have we learned? Placenta 13:115-122
31. Cetin I, Marconi AM, Baggiani AM, Buscaglia M, Pardi G, Fennessey PV, Battaglia FC1995 In vivo placental transport of glycine and leucine in human pregnancies. Pediatr Res 37:571-575

32. Chien PFW, Smith K, Watt PW, Scrimgeour CM, Taylor DJ, Rennie MJ 1993 Protein turnover in the human fetus studied at term using stable isotope tracer amino acids. Am J Physiol 265:E31-E35

33. Marconi AM, Paolini CL, Stramare L, Cetin I, Fennessey PV, Pardi G, Battaglia FC 1999 The steady state maternal-fetal leucine enrichments in normal and fetal growthrestricted pregnancies. Pediatr Res 46:114-119

34. Paolini CL, Marconi AM, Cetin I, Ronzoni S, Pike A, Fennessey PV, Pardi G, Battaglia FC 2000 In vivo placental transport of leucine, glycine, phenylalanine, and proline in normal and intrauterine growth-restricted pregnancies. J Soc Gynecol Investig 7:51A(abstr)

35. Ross JC, Fennessey PV, Wilkening RB, Battaglia FC, Meschia G 1996 Placental transport and fetal utilization of leucine in a model of fetal growth retardation. Am J Physiol 270:E491-E503

36. Pardi G, Cetin I, Marconi AM, Lanfranchi A, Bozzetti P, Ferrazzi E, Buscaglia M, Battaglia FC 1993 Diagnostic value of blood sampling in fetuses with growth retardation. N Engl J Med 328:692-696

37. Jansson T 2000 Amino acid transporters in the human placenta. Pediatr Res (in press 